cies. Para la germinación in vivo se realizaron ensayos desde junio a agosto de 2003 (Cuadro 2).

Las semillas se desinfectaron en forma similar a la descrita para la germinación in vitro. Se colocaron grupos de 250 semillas de cada especie en cámara de germinación Jacobsen a $20^{\circ} \mathrm{C}$ y 14 horas luz. En el caso de R. rhodolirion las semillas se sometieron a un remojo en agua destilada en frío $4-8^{\circ} \mathrm{C}$ durante 4 semanas

\section{RESULTADOS}

Debido a que la germinación de las semillas fue lenta y desuniforme en el tiempo se presentan los resultados como curvas de germinación a través del tiempo. Los siguientes cuadro mues- tran la germinación in vitro e in vivo de tres especies de Rhodophiala.

Los porcentajes máximos de germinación in vitro fueron los siguientes: $R$. bagnoldii, $52 \%$ en 40 días; $R$. splendens (sin remojo previo) $80 \%$ en 70 días, $R$. splendens (con remojo previo) $84 \%$ en 50 días; $R$. montana $73 \%$ en 50 días. Los porcentajes máximos de germinación in vivo fueron: $R$. bagnoldii $32 \%$ a los 20 días; $R$ splendens $82 \%$ en 60 días; $R$. rhodolirion $53 \%$ en 40 días.

\section{REFERENCIAS BIBLIOGRÁFICAS}

PEÑAILILLO, P. 1999. Introducción a las geófitas nativas de valor comercial. En: Seminario, Los geófitos nativos y su importancia en la floricultura. Universidad de Talca, pp: 1-10.

Trabajo financiado por Proyecto FIA-BIOT-01-A-071

Agro Sur $34(1-2): 70-722006$

\title{
ESTABLECIMIENTO in vitro Y MICROPROPAGACION DE Rhododendron catawbiense "album".
}

\section{In vitro ESTABLISHMENT AND MICROPROPAGATION OF Rhododendron catawbiense "album"}

Jara, G.' y Seemann, P.'

Universidad Austral de Chile. Fac. de Ciencias Agrarias. Inst. de Producción y Sanidad Vegetal.

Casilla 567, Valdivia, Chile. Fono 52-63-221669, Fax 52-63-221233. Email: gjara@uach.cl

\section{INTRODUCCION}

Entre las plantas leñosas ornamentales más difundidas en el sur de Chile se encuentran las del género Rhododendron, a la cual pertenecen las azaleas y rododendros. En el Jardín Botánico de la Universidad Austral de Chile, existe una gran cantidad de genotipos de Rhododendron spp., los cuales destacan por sus hermosas flores, agrupadas en inflorescencias de variados y vistosos colores. La propagación tradicional de ellas se ha realizado básicamente a través de la propagación vegetativa, mediante el enraizamiento de estacas. Sin embargo, esta técnica ha presentado limitaciones debido al escaso material inicial a multiplicar y al bajo porcentaje de

Cuadro 1. Medios de cultivo utilizados para el establecimiento de yemas in vitro de Rhododendron catawbiense "album".

Table 1. Culture media used for scale in vitro establishment of Rhododendron catawbiense "album"

\begin{tabular}{lcccc}
\hline & \multicolumn{4}{c}{ AlA/ 2i $P\left(M G L^{-1}\right)$} \\
\hline Medio de Cultivo & $0 / 0$ & $1 / 5$ & $2 / 5$ & $4 / 5$ \\
Anderson (1975) & Trat 1 & Trat 2 & Trat.3 & Trat.4 \\
Econumou y Read (1984) & Trat. 5 & Trat. 6 & Trat. 7 & Trat. 8 \\
\hline
\end{tabular}


Cuadro 2. Brotación in vitro de yemas de Rhododendron catawbiense "album".

Table 2. Budding in vitro of Rhododendron catawbiense "album.

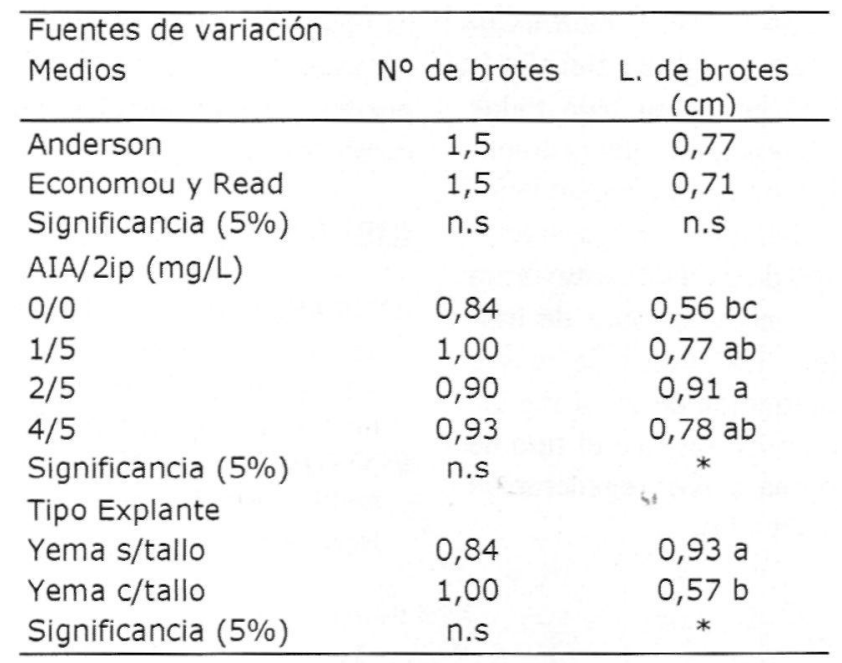

enraizamiento de ellas. Debido a esto se han desarrollado otras alternativas de multiplicación, tales como la micropropagación, a partir de yemas apicales, florales o de tejido vegetativo como explantes foliares, siendo además una valiosa herramienta para la eliminación de virus.

\section{OBJETIVOS}

Establecer e inducir la brotación in vitro de Rhododendron catawbiense "album", en dos medios de cultivo adicionados con diferentes concentraciones fitohormonales

\section{MATERIAL Y METODOS}

El establecimiento in vitro se realizó a partir de estaquillas leñosas de Rhododendron catawbiense "album", recolectados a mediados de primavera desde un arbusto adulto ubicado en el Jardín Botánico de la Universidad Austral de
Chile. Estas estaquillas fueron lavadas y desinfectadas superficialmente con una solución fungicida por 2 horas para posteriormente ser desinfectadas bajo condiciones asépticas con etanol al $70 \%$ y una solución de hipoclorito de sodio al $1 \%$ por $10 \mathrm{~min}$. Bajo estas condiciones, se aislaron yemas sin tallo y con tallo, las que fueron sembradas en frascos con $10 \mathrm{~mL}$, de medio de cultivo adicionados con ácido indol acético (AIA) y 2-isopentil adenina (2 iP), realizando 10 repeticiones por tratamiento, de acuerdo al siguiente cuadro:

Las condiciones de incubación fueron: flujo de fotones fotosinteticamente activos de 50 $\mu$ molm ${ }^{-2} \mathrm{~s}^{-1}, 23^{\circ} \mathrm{C}$. Después de transcurridos 4 meses se evaluó el número y longitud de brotes y porcentaje de sobrevivencia, de tal forma de procesar los datos mediante un Análisis de varianza y Test de Fischer con un nivel de probabilidad del $5 \%$.

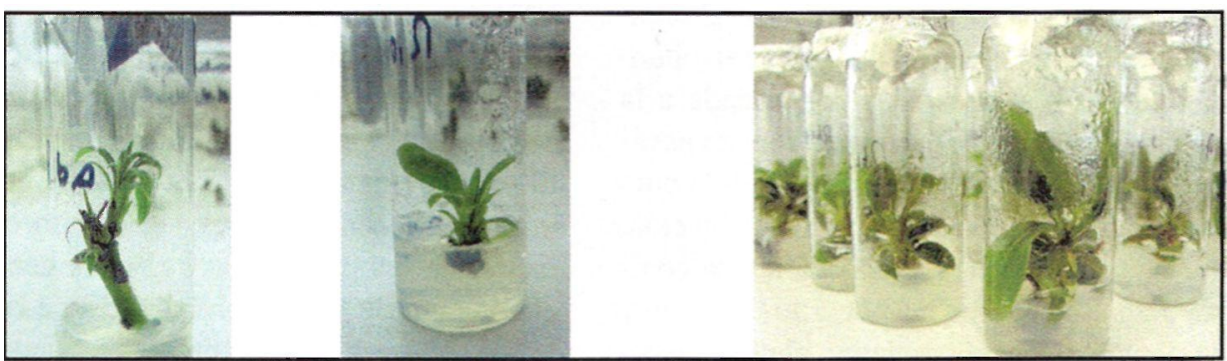

Figura 1. Emergencia de brotes y multiplicación in vitro de Rhododendron catawbiense "album".

Figure 1. Emergency and in vitro shoots of Rhododendron catawbiense "album". 


\section{RESULTADOS}

El establecimiento de yemas in vitro de Rhododendron catawbiense "album" fluctuó entre un 65-100\%, lográndose la brotación bajo todos los tratamientos, sin diferencias estadísticamente significativas para los medios y concentraciones de fitohormonas. Solamente el parámetro longitud de brotes y tipo de explante estuvieron influenciadas por las concentraciones de fitohormonas, obteniéndose los brotes de mayor tamaño con una concentración de $2-4 \mathrm{mg} \mathrm{L}^{-1}$ de AIA y $5 \mathrm{mg}$ de 2iP, mientras que el tipo de explante que presentó una mayor regeneración fueron yemas aisladas sin tallo.
De esta forma se pudo establecer que el establecimiento de yemas aisladas de árboles adultos es una alternativa eficiente para realizar la incorporación in vitro y que los brotes inducidos pueden ser multiplicados eficazmente bajo estas condiciones.

\section{BIBLIOGRAFÍA}

ANDERSON, W.C. 1975. Propagation of rhododendrons by tissue culture: Part 1 . Development of a culture medium for multiplication of shoots. Proc. Intl. Plant. Prop. Soc. 25: 129-135.

ECONOMOU A.S.; READ. P.E. 1984. In vitro shoot proliferation of Minnesota deciduos azaleas. Hortscience 19: 60-61.

Agro Sur 34 (1-2):72-73 2006

\title{
PROYECTO RECUPERACIÓN Y MEJORAMIENTO DEL CACTARIO, PATRIMONIO NATURAL DE LA UNIVERSIDAD AUSTRAL DE CHILE.
}

\section{CACTUS COLLECTION RECOVERING AND IMPROVING PROYECT , NATURAL PATRIMONY OF THE UNIVERSIDAD AUSTRAL DE CHILE.}

\author{
Hermosilla, E. \\ Universidad Austral de Chile, Casilla 1235 Valdivia, \\ mariahermosilla@uach.cl
}

El Instituto de Botánica, el Proyecto de Administración Ambiental Corporativo y la Dirección de Extensión de la Universidad Austral de Chile, están desarrollando desde el año 2002 el Proyecto Recuperación y Mejoramiento de Cactario, Patrimonio Natural de la Universidad Austral de Chile.

El Proyecto tiene como objetivo principal mantener y ampliar la colección de plantas suculentas (Cactáceas y Crasas) que fue donada a la Universidad en 1992 por un coleccionista particular, el Sr. Roberto Binder, habilitándola para desarrollar en ella actividades de investigación, docencia y extensión. La colección está compuesta actualmente por más de 150 especies y posee dentro de sus ejemplares, algunas especies chilenas y especies exóticas raras o cuyo valor radica en la edad de los ejemplares, que superan en algunos casos los 40 años.

Considerando que en Chile la familia de las Cactaceae está representada por cerca de 200 especies, ubicadas en 22 géneros, y que de éstas, más de 180 son endémicas y se encuentran exclusivamente en territorio chileno, el conocimiento y difusión de su importancia y valor es relevante. Además, en el Libro Rojo de la Flora Terrestre de Chile, se mencionan 12 géneros en los cuales una o más especies tienen problemas de conservación. De ellas, 151 son endémicas. El escaso conocimiento que se tiene acerca de muchas de estas especies, el deterioro y alteración de hábitats en las regiones centrales y el aumento de la comercialización a coleccionistas privados o con otros fines, puede causar daños irreversibles en su sobrevivencia, por lo que dentro de los objetivos prioritarios del pro- 